\title{
Determinantes do emprego secundário e informalidade: evidências adicionais para 0 mercado de trabalho brasileiro
}

\author{
Rafael Mesquita Pereira* \\ Maria Cristina Galvão** \\ Henrique dos Santos Maxir ${ }^{\star \star \star}$
}

O objetivo deste estudo é analisar os fatores que determinam a escolha de um indivíduo por um emprego secundário e como tal decisão está relacionada com a informalidade. Para tanto, a partir dos dados da Pesquisa Nacional por Amostra de Domicílios (PNAD) contínua, é estimado um modelo logit de efeitos aleatórios para verificar os fatores que influenciam nesta decisão de inserção. Os resultados apontam que o rendimento do trabalho principal, a escolaridade e a informalidade no emprego principal influenciam positivamente na decisão dos trabalhadores em ingressar em um emprego secundário.

Palavras-chave: Modelo logit de efeitos aleatórios. Segundo emprego. Emprego informal.

\footnotetext{
*Universidade Federal do Rio Grande (Furg), Rio Grande-RS, Brasil (rafaelmesquita@furg.br; http://orcid.org/0000-00026080-0208).

** Escola Superior de Agricultura “Luiz de Queiroz” (Esalq) da Universidade de São Paulo (USP), Piracicaba-SP, Brasil (galvao. mariacristina@usp.br; http://orcid.org/0000-0001-6241-9171).

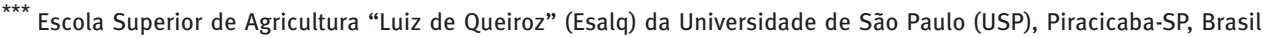
(henriquemaxir@usp.br; https://orcid.org/0000-0002-7739-6635).
} 


\section{Introdução}

0 mercado de trabalho brasileiro apresentou grandes transformações nas últimas décadas. Entretanto, uma problemática que persiste e tem gerado intensas discussões na literatura econômica nacional é a questão da informalidade. Autores como Cacciamali (2000), Menezes-Filho, Mendes e Almeida (2004), Ulyssea (2005), Meneguin e Bugarin (2008), Henley, Arabsheibani e Carneiro (2009), Paula e Scheinkman (2011), Menezes e Dedecca (2012), Barbosa e Corseuil (2014), entre outros, têm buscado evidenciar de diversas formas as peculiaridades com relação a esta característica do mercado de trabalho brasileiro. Porém, pouco se tem estudado sobre os determinantes da informalidade e formalidade no emprego secundário.

0 mercado de trabalho no Brasil é regulamentado desde a Consolidação das Leis do Trabalho (CLT) de 1943 (BRASIL, 1943). Atualmente tal legislação especifica que os empregadores devem registrar formalmente os trabalhadores em documento oficial, a carteira de trabalho. A assinatura da carteira de trabalho por um empregador significa conferir ao empregado benefícios que estão além dos salários, como jornada máxima de trabalho semanal, férias pagas, licença maternidade, aviso prévio no caso de demissão, horas extras, entre outros (HENLEY; ARABSHEIBANI; CARNEIRO, 2009).

A escassez de empregos formais e a existência de barreiras à entrada no mercado de trabalho, como a presença de sindicatos, discriminação racial e de gênero, são hipóteses que sustentam a ideia do diferencial de salários nos setores formal e informal. Seguindo esta lógica, características dos indivíduos possuem efeitos sob o nível de remuneração, ou seja, empregados com o mesmo nível de produtividade passariam a receber salários diferentes dependendo do setor em que estão inseridos (PAULA; SCHEINKMAN, 2011; MENEZES; DEDECCA, 2012).

Diversos autores procuraram qualificar a definição da informalidade no mercado de trabalho brasileiro. No entanto, não há consenso (ULYSSEA, 2005; PAULA; SCHEINKMAN, 2011). Henley, Arabsheibani e Carneiro (2009) argumentam que a Pesquisa Nacional por Amostra de Domicílios (PNAD) permite a mensuração da informalidade no mercado de trabalho de três maneiras, considerando: os trabalhadores sem carteira assinada; os trabalhadores sem contribuição para a Previdência Social; e os trabalhadores sem carteira assinada e sem contribuição para a Previdência Social.

De acordo com Cacciamali (2000), há outra forma de se observar o trabalho informal, a partir dos chamados trabalhadores por conta própria, que surgem devido a fatores como: a ausência de empregos assalariados e de políticas públicas compensatórias; a possibilidade de ganhos médios superiores aos dos trabalhadores assalariados, mesmo com baixa qualificação formal; crescimento do setor de serviços; e possibilidade de obtenção de remuneração em situações de difícil entrada ou realocação no mercado de trabalho. 0 autoemprego e as contratações consensuais podem ocorrer em diversas esferas, como em cooperativas ou agências de trabalho temporário. Tais atividades são declaradas como 
trabalho autônomo, que é, em geral, caracterizado por alta vulnerabilidade em relação às atividades desenvolvidas e na forma de remuneração. São negligenciados aspectos importantes como a segurança do trabalho, proteção social e uma remuneração justa de acordo com a média salarial da categoria ou setor de atuação.

$\mathrm{Na}$ literatura, uma série de estudos adotaram diversas metodologias para observar a questão da informalidade e seus determinantes para o caso do emprego principal no mercado de trabalho brasileiro, tais como Cacciamali (2000), Menezes-Filho, Mendes e Almeida (2004), Ulyssea (2005), Ramos (2007), Meneguin e Bugarin (2008), Henley, Arabsheibani e Carneiro (2009), Paula e Scheinkman (2011), Barbosa-Filho e Moura (2012), Menezes e Dedecca (2012) e Barbosa e Corseuil (2014). Entretanto, pouco se conhece sobre os elementos que contribuem para a escolha do trabalhador por um segundo emprego formal ou informal.

De acordo com a PNAD de 2015, os empregos secundários representam um contingente de $2 \%$ a $3 \%$ da população em idade ativa no Brasil. Embora pequeno, este percentual representa mais de um milhão de trabalhadores brasileiros, merecendo, assim, uma análise mais abrangente. Ademais, é importante destacar que, segundo informações da PNAD de 2015, este tipo de emprego mostra um alto grau de informalidade, o que instiga o estudo de como ele é composto e quais fatores influenciam na sua existência.

Desse modo, o objetivo geral da presente pesquisa é investigar quais características socioeconômicas e demográficas impactam na escolha do indivíduo em ingressar em um emprego secundário formal ou informal no Brasil. 0 período de análise se estende entre 2012 e 2015, caracterizado pela crescente taxa de desemprego e redução do número de admissões nos postos formais de trabalho. Além disso, ao se analisarem os determinantes do emprego secundário, busca-se preencher uma lacuna na literatura sobre o mercado de trabalho brasileiro, visto que não se tem conhecimento de trabalhos empíricos com essa temática.

A seguir são mostradas as características do mercado de trabalho secundário, juntamente com os fatos estilizados sobre a informalidade no mercado de trabalho brasileiro e a sua recente evolução. Posteriormente, apresentam-se a metodologia, com o procedimento econométrico adotado e os dados, os resultados e as discussões com a literatura atual. Por fim, são tecidas as considerações finais do estudo.

\section{Características do mercado de trabalho secundário no Brasil}

Uma possibilidade para o trabalhador, que tem tempo disponível e está disposto a preenchê-lo ofertando mão de obra, é buscar um segundo emprego para complementar sua renda. Tal alternativa pode ser alcançada tanto na formalidade quanto na informalidade das relações de trabalho, ou seja, é possível que trabalhadores possuam um trabalho principal formal e busquem, na informalidade, uma alternativa para complementar seu rendimento mensal. Dessa forma, a Tabela 1 apresenta um panorama do mercado de trabalho brasileiro 
em relação à composição dos empregos principal e secundário, assim como dos tipos de contratos de trabalho (formais ou informais) que estão sendo estabelecidos.

TABELA 1

Proporção de trabalhadores, segundo tipo de trabalho exercido Brasil - 2012-2015

\begin{tabular}{lrrrc} 
& & & Em porcentagem \\
\hline \multicolumn{1}{c}{ Tipo de trabalho } & $\mathbf{2 0 1 2}$ & $\mathbf{2 0 1 3}$ & $\mathbf{2 0 1 4}$ & $\mathbf{2 0 1 5}$ \\
\hline Trabalhadores apenas com trabalho principal & $\mathbf{9 7 , 9 9}$ & $\mathbf{9 7 , 9 5}$ & $\mathbf{9 7 , 7 9}$ & $\mathbf{9 8 , 0 1}$ \\
Principal formal & 66,76 & 67,94 & 67,81 & 68,61 \\
Principal informal & 33,24 & 32,06 & 32,19 & 31,39 \\
\hline Trabalhadores com trabalho principal e secundário & $\mathbf{2 , 0 1}$ & $\mathbf{2 , 0 5}$ & $\mathbf{2 , 2 1}$ & $\mathbf{1 , 9 9}$ \\
Secundário formal & 18,06 & 15,96 & 15,67 & 17,64 \\
Secundário informal & 81,94 & 84,04 & 84,33 & 82,36 \\
\hline
\end{tabular}

Fonte: IBGE. Pesquisa Nacional por Amostra de Domicílios - PNAD 2012 a 2015. Elaboração dos autores.

De acordo com as estatísticas apresentadas na Tabela 1, observa-se que a maior parte dos trabalhadores brasileiros possui somente um emprego, sendo que, desta parcela, pouco mais de $2 / 3$ são caracterizados por empregos formais e $1 / 3$ por informais, no período analisado. Com relação ao trabalho secundário, embora seja desempenhado em média por apenas de $1,99 \%$ a $2,21 \%$ de trabalhadores brasileiros, este representa um contingente de aproximadamente 1,3 milhão de trabalhadores.

Na Tabela 2, é possível verificar como estão sendo combinados estes dois empregos (principal e secundário) pelos trabalhadores. As estatísticas mostram que quase $50 \%$ dos trabalhadores que possuem um trabalho principal formal juntamente com um secundário optam pela informalidade deste último. Também, observa-se que entre 31\% e 35\% dos que possuem trabalho principal informal recorrem aos postos informais de trabalho como uma alternativa. Essa característica também é constatada em períodos anteriores, conforme ressalta Ramos (2007), mostrando que a informalidade apresenta certa estabilidade no período de sua pesquisa (1992-2005), mas em níveis elevados. Além disso, nota-se que o emprego formal oscila muito pouco de um ano para outro.

TABELA 2

Distribuição dos trabalhadores com trabalhos principal e secundário, segundo composição Brasil - 2012-2015

\begin{tabular}{lrrrr}
\multicolumn{1}{c}{ Composição } & $\mathbf{2 0 1 2}$ & $\mathbf{2 0 1 3}$ & $\mathbf{2 0 1 4}$ & $\mathbf{2 0 1 5}$ \\
\hline Trabalho principal e secundário & & & & \\
Formal - formal & 14,50 & 12,39 & 12,90 & 14,19 \\
Formal - informal & 47,13 & 49,55 & 49,32 & 51,03 \\
Informal - informal & 34,81 & 34,49 & 35,01 & 31,34 \\
Informal - formal & 3,56 & 3,57 & 2,77 & 3,45 \\
\hline Total & $\mathbf{1 0 0 , 0 0}$ & $\mathbf{1 0 0 , 0 0}$ & $\mathbf{1 0 0 , 0 0}$ & $\mathbf{1 0 0 , 0 0}$ \\
\hline
\end{tabular}

Fonte: IBGE. Pesquisa Nacional por Amostra de Domicílios - PNAD 2012 a 2015. Elaboração dos autores. 
Para analisar como estão distribuídos setorialmente os postos formais de trabalho no Brasil, realizou-se uma desagregação por atividade econômica, ${ }^{1}$ tanto do trabalho principal quanto do secundário. A Tabela 3 apresenta estas estatísticas.

Com relação ao trabalho principal, as atividades com percentuais de informalidade maiores do que a média nacional no período analisado são a agropecuária (de 59,22\% a 56,00\%), administração, defesa e seguridade social (de 57,25\% a 61,73\%), educação (de $37,84 \%$ a 40,03\%), serviços domésticos (de $66,42 \%$ a $69,64 \%$ ) e outros serviços (de $45,43 \%$ a 55,43\%). Estas estatísticas são bem semelhantes às encontradas por Barbosa-Filho e Moura (2012) para 2009, que destacam que o nível elevado de informalidade na agropecuária se dá pelo fato de se caracterizar por um trabalho familiar de pequenas propriedades e que os serviços possuem informalidade bastante expressiva. De acordo com os autores, os maiores níveis de contratos informais de trabalho são observados em atividades intensivas em mão de obra. Nesse sentido, ressalta-se o elevado patamar encontrado para os serviços domésticos, que, mesmo após a criação da lei que regulamenta a atividade, ${ }^{2}$ ainda caracterizam-se, em grande parte, por uma atividade informal. 0 percentual de informalidade no setor de serviços é semelhante ao apresentado por Ramos (2007), setor destacado pelo autor como um dos grandes responsáveis pelo aumento da informalidade no país devido ao seu crescimento nos últimos anos.

0 alto percentual de informalidade registrado na administração, defesa e seguridade social pode estar relacionado ao regime contratual dos empregos desta atividade, uma vez que os serviços públicos sob o regime "estatutário" não são registrados na carteira de trabalho. Dessa forma, apenas os empregos públicos sob o regime da CLT entrariam nesta estatística.

Com relação ao trabalho secundário, é possível observar que de 0,91\% a 3,04\% dos postos de trabalho da agropecuária são formais. As atividades que, juntamente com a agropecuária, apresentam os maiores patamares de informalidade no trabalho secundário são a indústria da transformação (de $89,73 \%$ a 94,18\%), o comércio (de $91,34 \%$ a $94,91 \%$ ), os outros serviços (de $91,78 \%$ a $97,19 \%$ ) e os serviços domésticos (de $91,90 \%$ a 97,99\%) (Tabela 3).

Estas estatísticas mostram uma característica peculiar do mercado de trabalho secundário brasileiro: o seu alto nível de informalidade. Essa peculiaridade se confirma pela constatação de que mais de $80 \%$ destes postos de trabalho secundário, no período analisado, são informais. Nesse sentido, é preciso entender quais são os elementos que fomentam e caracterizam a informalidade nas relações de trabalho do país.

\footnotetext{
${ }^{1}$ De acordo com a classificação da CNAE Domiciliar.

${ }^{2}$ Lei Complementar nํㅜ 150, de 1ํ de junho de 2015, que dispõe sobre o contrato de trabalho doméstico.
} 
TABELA 3

Percentual de formalidade no trabalho principal e secundário, segundo setores de atividade Brasil - 2012-2015

\begin{tabular}{|c|c|c|c|c|c|c|c|c|}
\hline \multirow[t]{2}{*}{ Setores de atividade } & \multicolumn{4}{|c|}{ Trabalho principal } & \multicolumn{4}{|c|}{ Trabalho secundário } \\
\hline & 2012 & 2013 & 2014 & 2015 & 2012 & 2013 & 2014 & 2015 \\
\hline Participação no total & 97,99 & 97,95 & 97,79 & 98,01 & 2,01 & 2,05 & 2,21 & 1,99 \\
\hline \multirow{2}{*}{$\begin{array}{l}\text { Agricultura, pecuária, produção } \\
\text { florestal, pesca e aquicultura }\end{array}$} & 40,78 & 41,76 & 44,00 & 42,11 & 3,04 & 0,00 & 2,33 & 0,91 \\
\hline & $(0,49)$ & $(0,49)$ & $(0,50)$ & $(0,49)$ & $(0,17)$ & $(0,00)$ & $(0,15)$ & $(0,10)$ \\
\hline \multirow[t]{2}{*}{ Indústria extrativa } & 87,18 & 87,14 & 86,63 & 87,68 & - & - & 0,00 & 100,00 \\
\hline & $(0,33)$ & $(0,33)$ & $(0,34)$ & $(0,33)$ & - & - & $(0,00)$ & $(0,00)$ \\
\hline \multirow[t]{2}{*}{ Indústria de transformação } & 86,07 & 86,52 & 86,72 & 87,39 & 8,55 & 9,87 & 5,82 & 10,27 \\
\hline & $(0,35)$ & $(0,34)$ & $(0,34)$ & $(0,33)$ & $(0,28)$ & $(0,30)$ & $(0,23)$ & $(0,30)$ \\
\hline \multirow[t]{2}{*}{ Eletricidade e gás } & 93,27 & 96,49 & 92,96 & 92,65 & - & - & 42,36 & \\
\hline & $(0,25)$ & $(0,18)$ & $(0,26)$ & $(0,26)$ & - & - & $(0,49)$ & \\
\hline \multirow{2}{*}{$\begin{array}{l}\text { Água, esgoto, atividades de gestão } \\
\text { de resíduos }\end{array}$} & 81,59 & 79,53 & 80,40 & 78,53 & 0,00 & 0,00 & 0,00 & 0,00 \\
\hline & $(0,39)$ & $(0,40)$ & $(0,40)$ & $(0,41)$ & $(0,00)$ & $(0,00)$ & $(0,00)$ & $(0,00)$ \\
\hline \multirow[t]{2}{*}{ Construção } & 65,24 & 67,24 & 65,91 & 65,74 & 9,06 & 8,10 & 5,97 & 7,96 \\
\hline & $(0,48)$ & $(0,47)$ & $(0,47)$ & $(0,47)$ & $(0,29)$ & $(0,27)$ & $(0,24)$ & $(0,27)$ \\
\hline \multirow{2}{*}{$\begin{array}{l}\text { Comércio, reparação de veículos } \\
\text { automotores e motocicletas }\end{array}$} & 75,93 & 77,47 & 77,48 & 78,78 & 8,05 & 8,66 & 8,06 & 5,09 \\
\hline & $(0,43)$ & $(0,42)$ & $(0,42)$ & $(0,41)$ & $(0,27)$ & $(0,28)$ & $(0,27)$ & $(0,22)$ \\
\hline \multirow[t]{2}{*}{ Transporte, armazenagem e correio } & 82,61 & 82,75 & 83,47 & 85,00 & 22,13 & 16,36 & 25,47 & 20,09 \\
\hline & $(0,38)$ & $(0,38)$ & $(0,37)$ & $(0,36)$ & $(0,42)$ & $(0,37)$ & $(0,44)$ & $(0,40)$ \\
\hline \multirow[t]{2}{*}{ Alojamento e alimentação } & 67,65 & 68,52 & 68,50 & 68,29 & 6,41 & 15,66 & 11,68 & 12,25 \\
\hline & $(0,47)$ & $(0,46)$ & $(0,46)$ & $(0,47)$ & $(0,24)$ & $(0,36)$ & $(0,32)$ & $(0,33)$ \\
\hline \multirow[t]{2}{*}{ Informação e comunicação } & 67,00 & 71,10 & 70,46 & 72,19 & 13,10 & 9,41 & 7,49 & 13,78 \\
\hline & $(0,47)$ & $(0,45)$ & $(0,46)$ & $(0,45)$ & $(0,34)$ & $(0,29)$ & $(0,26)$ & $(0,34)$ \\
\hline \multirow{2}{*}{$\begin{array}{l}\text { Atividades financeiras, de seguros } \\
\text { e serviços relacionados }\end{array}$} & 89,56 & 89,76 & 90,53 & 91,65 & 23,49 & 34,82 & 36,66 & 16,76 \\
\hline & $(0,31)$ & $(0,30)$ & $(0,29)$ & $(0,28)$ & $(0,42)$ & $(0,48)$ & $(0,48)$ & $(0,37)$ \\
\hline \multirow{2}{*}{$\begin{array}{l}\text { Atividades profissionais, científicas } \\
\text { e técnicas }\end{array}$} & 84,44 & 86,20 & 85,81 & 86,30 & 33,84 & 27,45 & 25,78 & 20,85 \\
\hline & $(0,36)$ & $(0,34)$ & $(0,35)$ & $(0,34)$ & $(0,47)$ & $(0,45)$ & $(0,44)$ & $(0,41)$ \\
\hline \multirow{2}{*}{$\begin{array}{l}\text { Atividades administrativas e } \\
\text { serviços complementares }\end{array}$} & 77,17 & 84,64 & 80,92 & 83,68 & 36,27 & 0,00 & 0,00 & 0,00 \\
\hline & $(0,42)$ & $(0,36)$ & $(0,39)$ & $(0,37)$ & $(0,48)$ & $(0,00$ & $(0,00)$ & $(0,00)$ \\
\hline \multirow{2}{*}{$\begin{array}{l}\text { Administração pública, defesa e } \\
\text { seguridade social }\end{array}$} & 42,75 & 42,63 & 38,14 & 38,27 & 13,57 & 17,84 & 10,55 & 9,06 \\
\hline & $(0,49)$ & $(0,49)$ & $(0,49)$ & $(0,49)$ & $(0,34)$ & $(0,38)$ & $(0,31)$ & $(0,29)$ \\
\hline \multirow[t]{2}{*}{ Educação } & 62,16 & 60,68 & 59,97 & 61,54 & 35,70 & 28,57 & 34,15 & 35,80 \\
\hline & $(0,48)$ & $(0,49)$ & $(0,49)$ & $(0,49)$ & $(0,48)$ & $(0,45)$ & $(0,47)$ & $(0,48)$ \\
\hline \multirow[t]{2}{*}{ Saúde humana e serviços sociais } & 78,11 & 77,47 & 76,29 & 78,73 & 36,88 & 30,08 & 30,08 & 39,52 \\
\hline & $(0,41)$ & $(0,42)$ & $(0,43)$ & $(0,41)$ & $(0,48)$ & $(0,46)$ & $(0,46)$ & $(0,49)$ \\
\hline \multirow[t]{2}{*}{ Outras atividades de serviços } & 46,41 & 50,17 & 44,57 & 54,57 & 8,22 & 5,52 & 2,81 & 4,84 \\
\hline & $(0,50)$ & $(0,50)$ & $(0,50)$ & $(0,50)$ & $(0,27)$ & $(0,23)$ & $(0,17)$ & $(0,21)$ \\
\hline \multirow[t]{2}{*}{ Serviços domésticos } & 30,36 & 33,58 & 32,57 & 32,94 & 2,01 & 4,99 & 8,10 & 6,60 \\
\hline & $(0,46)$ & $(0,47)$ & $(0,47)$ & $(0,47)$ & $(0,14)$ & $(0,22)$ & $(0,27)$ & $(0,25)$ \\
\hline \multirow{2}{*}{$\begin{array}{l}\text { Organismos internacionais e outras } \\
\text { instituições extraterritoriais }\end{array}$} & 61,65 & 67,68 & 87,97 & 74,54 & 0,00 & 0,00 & - & 0,00 \\
\hline & $(0,49)$ & $(0,47)$ & $(0,33)$ & $(0,44)$ & $(0,00)$ & $(0,00)$ & - & $(0,00)$ \\
\hline
\end{tabular}

Fonte: IBGE. Pesquisa Nacional por Amostra de Domicílios - PNAD 2012 a 2015. Elaboração dos autores.

Nota: Os valores entre parênteses representam o desvio-padrão. As estatísticas com valor zero nos trabalhos secundários significam que existe incidência de trabalho secundário no setor, mas nenhum deles é formal. 
Em termos gerais, a informalidade no mercado de trabalho brasileiro possui um comportamento endógeno, ou seja, existem fatores políticos e econômicos que influenciam diretamente na sua existência. Na década de 1990, por exemplo, o mercado de trabalho informal brasileiro elevou-se significativamente, motivado por uma retração da atividade da indústria da transformação e, consequentemente, por uma expansão do setor de serviços (RAMOS, 2002). Isso ocorreu porque a indústria caracteriza-se pelos contratos formais (contratos de trabalho regidos pela Consolidação das Leis do Trabalho - CLT) (BRASIL, 1943), enquanto o setor de serviços caracteriza-se por atividades autônomas, sem a utilização das formas legais para o desempenho da atividade (sem carteira assinada). Curi e Menezes-Filho (2004) acrescentam que a transição do trabalho informal para o formal declinou significativamente nos anos 1990 e a transição formal-informal aumentou substancialmente no período.

A partir da década de 2000, iniciou-se um processo inverso ao dos anos anteriores: houve uma redução constante do desemprego, acompanhada de uma diminuição da informalidade (BARBOSA-FILHO; MOURA, 2012). Este movimento, de certa forma, seguiu o novo cenário econômico do país no período, caracterizado pelo crescimento econômico que acarretou, por conseguinte, o aumento do número de postos formais de trabalho, como pode ser observado no Gráfico 1.

Nota-se que, quando a taxa de desemprego diminui, o grau de informalidade também diminui e o número de admissões de formais aumenta, ou seja, há uma resposta bem clara da informalidade à situação macroeconômica do país. Por exemplo, a partir de 2011, quando a taxa de desemprego voltou a crescer, o grau de informalidade e 0 número de admissões formais no período deslocaram-se no sentido contrário ao registrado no início dos anos 2000, confirmando esse movimento encadeado do mercado de trabalho brasileiro (Gráfico 1).

Além destes fatores macroeconômicos, existem aspectos microeconômicos que, embora também sejam influenciados por tais fatores, interferem no tamanho da informalidade do mercado de trabalho brasileiro. Segundo Rauch (1991) e Scandiuzzi (1999), o trabalho no setor informal depende diretamente da legislação dos salários mínimos e das leis trabalhistas no setor formal. Nesse caso, a informalidade surge por uma questão institucional, uma vez que os custos para as empresas celebrarem contratos de trabalho informais são bem menores do que para os formais. Assim, é possível correlacionar positivamente o setor informal com as taxas impostas pelo governo e negativamente com o poder de legislação por parte das instituições e sua qualidade, ou seja, a carga tributária e restrições nos trabalhos formais (atividades insalubres, de risco, etc.) afetam positivamente no tamanho relativo do setor informal, pois atuam como estímulos à informalidade (CAMARGO, 1996). 


\section{GRÁFICO 1}

Variação do grau de informalidade, das admissões formais e da taxa de desemprego

Brasil - 2002-2014

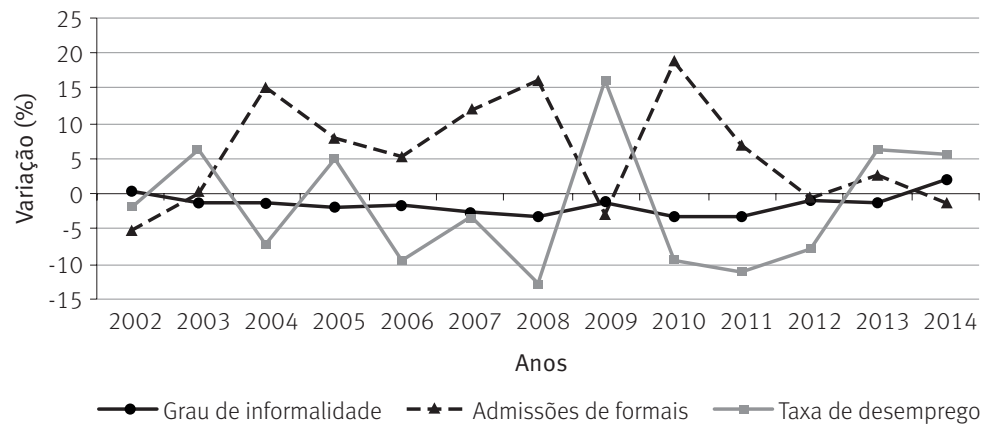

Fonte: IBGE (2017). Elaboração dos autores.

Para Ramos (2007), a informalidade existe baseada na ilegalidade e revela a gravidade do funcionamento deficiente do mercado de trabalho, seja por questões conjunturais ligadas ao desempenho econômico ou como decorrente de inflexibilidades e custos introduzidos pela legislação trabalhista de demais instituições que o afetam, além da carga tributária excessiva. 0 elevado nível de impostos, aliado ao desenho atual do seguro-desemprego, acaba funcionando como incentivos ao aumento da informalidade (CAMARGO, 1996). Nesse sentido, Ulyssea (2008) acrescenta que o tamanho da informalidade gera um custo importante ao Estado, uma vez que o governo deixa de arrecadar impostos inerentes ao contrato formal, tais como Imposto de Renda e Contribuição Previdenciária.

Nos últimos anos, a informalidade apresenta um tímido processo de diminuição. BarbosaFilho e Moura (2012) destacam que a diminuição de jovens (15 a 24 anos) na população ocupada e a interação entre ciclos escolares e experiência têm sido elementos importantes na compreensão da redução dos percentuais de informalidade no país. Os autores aliam esta queda, também, ao aumento da transição de trabalhadores do setor informal para o formal e à absorção de desempregados pelo setor formal.

Existem alguns fatos estilizados relacionados às exigências de qualificação (escolaridade e experiência, por exemplo) para o ingresso no mercado de trabalho formal. De acordo com Fernandes (1996), Tannuri-Pianto e Pianto (2002) e Cacciamali e Fernandes (1993), os trabalhadores de atividades formais possuem maior nível de escolaridade média do que os trabalhadores informais, sugerindo a existência de segmentação no mercado de trabalho, ou seja, trabalhadores com baixa escolaridade tendem a se inserir em empregos informais por não cumprirem as exigências para ingressarem em atividades formais. Segundo Barbosa-Filho e Moura (2012), os indivíduos que possuem de quatro a sete anos de estudos representam o grupo que mais contribui para a informalidade. Nas regiões metropolitanas, os indivíduos com ensino médio são os que mais contribuem para o aumento dos postos informais de trabalho e, nas não metropolitanas, são as pessoas com quatro anos de estudos. 
Ulyssea (2005) destaca que a idade está negativamente relacionada com a probabilidade de o indivíduo trabalhar no setor informal, sugerindo que este setor caracteriza-se por baixa escolaridade e pouca idade. Porém, o autor alerta que o ingresso em atividades informais pode ser uma escolha do indivíduo, possivelmente pela maior flexibilidade de barganha tanto para o empregado como para as empresas.

Estes aspectos, de um modo geral, se tornam um problema econômico relevante, uma vez que a informalização deflagra a precarização da qualidade do trabalho, a fragilização da inserção no mercado de trabalho e a banalização dos vínculos empregatícios (MENEGUIN; BUGARIN, 2008). Ademais, conforme destaca Ulyssea (2008), além desta perda dos benefícios associados ao emprego formal, a informalidade caracteriza-se por uma alta rotatividade, pois esse desenlace dos aspectos legais dos contratos acaba tornando as relações de trabalho menos duradouras.

Para Menezes e Dedecca (2012), o tamanho da informalidade no mercado de trabalho brasileiro está relacionado à insuficiência de desenvolvimento econômico do país, de modo que a dimensão do setor informal é decorrência de um problema de demanda por atividades formais. Além disso, a impossibilidade de encontrar um emprego formal e a perspectiva de baixos salários motivam os trabalhadores a buscarem alocação no setor informal como alternativa.

Com o intuito de padronizar a definição de informalidade para o restante do trabalho, será utilizada a definição na qual possuir carteira de trabalho assinada representa um contrato formal de trabalho e, não possuir, caracteriza um trabalho informal. Esta definição foi empregada nos estudos de Pero (1992), Barros, Mello e Pero (1993), Fernandes (1996), Scandiuzzi (1999), Carneiro e Henley (2001), Tannuri-Pianto e Pianto (2002), Soares (2004), Henley, Arabsheibani e Carneiro (2009), Barbosa-Filho e Moura (2012), Barbosa e Corseuil (2014) e discutida em Cacciamali (2000) e Ramos (2007).

Diante destes aspectos, é notório que existem algumas características do trabalho secundário que necessitam ser investigadas para que se possa traçar um perfil deste tipo de emprego. Não há registros, ao que se tem conhecimento, de estudos que analisem especificamente este mercado de trabalho no Brasil.

Diante do exposto, este trabalho se propõe a verificar a seguinte hipótese: quais são os fatores que influenciam na decisão dos indivíduos de possuírem um trabalho secundário formal ou informal no Brasil? Na próxima seção são apresentados a metodologia, o procedimento econométrico e os dados utilizados para responder a esta indagação.

\section{Metodologia}

Para analisar os determinantes da escolha do indivíduo em possuir um segundo emprego, formal ou informal, adotou-se o modelo logit. ${ }^{3}$ Pressupõe-se neste estudo que

\footnotetext{
${ }^{3}$ Cameron e Trivedi (2005) apontam que uma das formas para a escolha entre os modelos de resultados binários corresponde à comparação entre os valores da log-verossimilhança. Dessa forma, utilizando este critério, optou-se pelo modelo logit porque sua estimação resultou um maior valor para o log-verossimilhança, proporcionando ganhos em relação ao modelo probit.
} 
determinadas variáveis, como renda, escolaridade, idade, sexo, raça, etc., são capazes de influenciar na decisão de possuir ou não um trabalho secundário.

Os dados estão dispostos em um painel desbalanceado, ou seja, os indivíduos podem ser observados em um número diferente de vezes. Entretanto, optou-se por deixar na amostra apenas indivíduos que aparecem pelo menos em dois períodos, que neste trabalho são medidos em trimestres.

De acordo com Greene (2012), a estrutura básica de um painel tem a forma: $y_{i t}=x_{i t}^{\prime} \beta+z_{j}^{\prime} \alpha+\varepsilon_{i t}$

Em que existem $K$ regressores em $x_{i t}$, não incluindo o termo constante. 0 efeito individual, ou heterogeneidade, está presente no termo $z_{i}^{\prime} \alpha$, no qual $z_{i}$ contém um termo constante e um conjunto de variáveis específicas de grupos ou indivíduos, que podem ser observáveis, tal como raça, ou não observáveis, tal como habilidades específicas ou preferências.

Segundo Greene (2012), o modelo estrutural para um painel desbalanceado de dados, considerando uma escolha binária, pode ser escrito:

$y_{i t}^{*}=x_{i t}^{\prime} \beta+v_{i t}+u_{i}, \quad i=1, \ldots, n, \quad t=1, \ldots, T_{i}$,

$y_{i t}=1$ se $y_{i t}^{*}>0$, e $y_{i t}=0$, caso contrário

No qual $u_{i}$ representa a heterogeneidade específica individual que é não observada. A relação entre $u_{i}$ e $x_{i t}$ distingue os modelos de efeitos fixos e efeitos aleatórios. Para o modelo de efeitos fixos, $u_{i}$ e $x_{i t}$ podem ser correlacionados. Já para o modelo de efeitos aleatórios, $u_{i}$ é não correlacionado a $x_{i t}$, fazendo com que a distribuição condicional $u_{i} \mathrm{e}$ $f\left(u_{i} \mid x_{i t}\right)$ seja não dependente de $x_{i t}$.

Ao aplicar este painel a uma escolha binária, tem-se que a variável dependente, $y_{i t}$, assume valores de 1 ou 0 com probabilidades $F\left(x_{i}^{\prime} \beta\right)$ e $1-F\left(x_{i}^{\prime} \beta\right)$, respectivamente, no qual $F$ é a função que define a probabilidade. Sendo $x_{i t}$ as variáveis independentes de interesse, a densidade teórica para $y_{i t}$, será:

$f\left(y_{i t} \mid x_{i t}\right)=F\left(x_{i t}^{\prime} \beta\right)$ para $y_{i t}=1$ e $1-F\left(x_{i t}^{\prime} \beta\right)$ para $y_{i t}=0$

Assumindo-se o modelo logit, tem-se:

$\operatorname{Prob}\left(y_{i t} \mid x_{i t}\right)=F\left(x_{i t}^{\prime} \beta\right)=\Lambda\left(x_{i t}^{\prime} \beta\right)=\frac{\exp \left(x_{i t}^{\prime} \beta\right)}{1+\exp \left(x_{i t}^{\prime} \beta\right)}$

Sendo que $F($ ) é uma função de distribuição logística. A estimação dos parâmetros é realizada utilizando o método de máxima verossimilhança. ${ }^{4}$

A construção dos painéis utilizados neste estudo se baseia em dados trimestrais e isso faz com que algumas das variáveis explicativas empregadas nas estimações apresentem pouca ou nenhuma variação, como é o caso da variável de região de moradia. Conforme Wooldridge (2007), uma vez que os valores das variáveis explicativas têm

\footnotetext{
${ }^{4}$ Para descrição detalhada da função de máxima verossimilhança considerando efeitos fixos e aleatórios, consultar Greene (2012).
} 
uma variação pequena nos períodos considerados, as estimativas obtidas por meio do modelo de efeitos fixos (EF) podem ser imprecisas e com elevadas variâncias. Logo, um número considerável da amostra foi excluído ao se aplicar o modelo de $\mathrm{EF}$, dado que possivelmente não houve variabilidade em algum regressor. Em análises de dados em painel, o teste de Hausman tem sido comumente utilizado como artifício para a escolha entre os modelos de EF e efeitos aleatórios (EA). Entretanto, devido à pouca variação de alguns regressores, entende-se que o modelo EA produzirá estimativas mais robustas do que o EF, não sendo necessária a realização do teste de Hausman para a determinação da escolha do modelo. Dessa forma, o modelo econométrico utilizado neste trabalho tem três especificações:

$\operatorname{Pr}\left(\right.$ trabsec $\left._{i, t}=1\right)=F\left(\beta_{0}+\beta_{1}\right.$ lnw $_{i, t}+\beta_{2}$ escolaridade $_{i, t}+\beta_{3}$ idade $_{i, t}+\beta_{4}$ idade $_{i, t}^{2}+$
$\beta_{5}$ sexo $_{i}+\beta_{6}$ raça $_{i}+\beta_{7}$ chefe $_{i}+\beta_{8}$ carteira $\left._{i, t}+\sum_{\mathrm{n}=1}^{26} \gamma_{\mathrm{n}} U F_{i, t}+\beta_{9} R_{i, t}+c_{i}+u_{i, t}\right)$
$\operatorname{Pr}\left(\right.$ trabsec_formal $\left._{i, t}=1\right)=F\left(\beta_{0}+\beta_{1} \ln _{i, t}+\beta_{2}\right.$ escolaridade $_{i, t}+\beta_{3}$ idade $_{i, t}+$
$\beta_{4}$ idade $_{i, t}^{2}+\beta_{5}$ sexo $_{i}+\beta_{6}$ raça $_{i}+\beta_{7}$ chefe $_{i}+\beta_{8}$ carteira $_{i, t}+\sum_{\mathrm{n}=1}^{26} \gamma_{\mathrm{n}} U F_{i, t}+\beta_{9}$ RM $\left._{i, t}+c_{i}+u_{i, t}\right)$
$\operatorname{Pr}\left(\right.$ trabsec_informal $\left._{i, t}=1\right)=F\left(\beta_{0}+\beta_{1} \operatorname{lnw}_{i, t}+\beta_{2}\right.$ escolaridade $_{i, t}+\beta_{3}$ idade $_{i, t}+$
$\beta_{4}$ idade $_{i, t}^{2}+\beta_{5}$ sexo $_{i}+\beta_{6}$ raça $_{i}+\beta_{7}$ chefe $_{i}+\beta_{8}$ carteira $_{i, t}+\sum_{\mathrm{n}=1}^{26} \gamma_{\mathrm{n}} U F_{i, t}+\beta_{9}$ RM $\left._{i, t}+c_{i}+u_{i, t}\right)$

Em que:

$i=1, \ldots, m$ representa os indivíduos para cada trimestre $t$;

trabsec $_{i, t}=$ dummy que identifica se o indivíduo possui segundo emprego (formal ou informal), assumindo valor 1 se possuir e 0 caso contrário;

trabsec_formal $_{i, t}=$ dummy que identifica se 0 indivíduo possui segundo emprego formal, assumindo valor 1 se possuir e 0 caso contrário;

trabsec_informal $i_{i, t}=$ dummy que identifica se o indivíduo possui segundo emprego informal, assumindo valor 1 se possuir e 0 caso contrário;

$F($ ) = representa uma função de distribuição logística;

$\beta_{0}, \ldots, \beta_{16} ; y_{1}, \ldots, y_{26}=$ parâmetros a serem estimados;

$\ln w=$ logaritmo natural do salário mensal no trabalho principal;

escolaridade = escolaridade do indivíduo;

idade = idade do indivíduo em anos;

idade ${ }^{2}=$ idade do indivíduo ao quadrado como proxy para experiência;

sexo $=$ dummy que identifica o gênero do indivíduo, sendo mulher a base;

raça = dummy que identifica a raça do indivíduo, sendo não branco a base;

chefe = dummy que identifica se o indivíduo é chefe de família;

carteira $=$ dummy que identifica se o indivíduo possui carteira assinada no trabalho

principal;

$U F=$ dummies que identificam o estado em que o indivíduo reside, sendo o Distrito Federal a base; 
$R M=$ dummy que identifica se $\mathrm{o}$ indivíduo reside em região metropolitana;

$c_{i}=$ representa efeitos fixos ou aleatórios de cada indivíduo $i$;

$u_{i, t}=$ termo de erro do modelo.

Ressalta-se que, para esse estudo, a magnitude dos parâmetros a serem estimados não corresponde ao foco da análise. 0 que se pretende avaliar é o sinal e a relação entre as variáveis explicativas em se ter um segundo emprego. Assim como apontado por Wooldridge (2007), conhecer os sinais dos parâmetros estimados é o suficiente para determinar se as variáveis independentes têm efeitos positivos ou negativos.

\section{Dados}

A base de dados utilizada para as estimações dos modelos econométricos é constituída das PNADs contínuas de 2012, 2013, 2014 e 2015. Para cada período de 12 meses criou-se um painel contendo observações acompanhadas por trimestre do respectivo ano. Estas bases trimestrais são compostas por indivíduos maiores de 16 anos de idade e por profissionais que possuem e não possuem carteira de trabalho assinada. Dessa forma, os funcionários públicos (exceto celetistas) e trabalhadores por conta própria foram excluídos da amostra. A Tabela 4 apresenta as médias e desvios-padrão (entre parênteses) das variáveis utilizadas, bem como suas definições.

A variável "rendimento/hora" é elaborada a partir da divisão do rendimento obtido pelo indivíduo no trabalho principal pelas horas trabalhadas por semana vezes 4,2 (baseado em um mês de 30 dias dividido pelos sete dias da semana). É importante frisar que, para efeitos de análise, o rendimento/hora tanto para o trabalho principal quanto para o secundário foi corrigido a preços de 2015 pelo deflator do PIB fornecido pelo IBGE. Assim, é possível observar que no trabalho principal os formais ganham, em média, de 37,7\% a 41,69\% a mais do que os informais no período analisado. Com relação ao trabalho secundário, os formais também possuem rendimentos médios mais elevados do que os informais, variando entre $34,52 \%$ e $46,02 \%$. Porém, estes percentuais vêm diminuindo com o passar dos anos, possivelmente como um reflexo do aumento da taxa de desemprego e do grau de informalidade, além da redução do número de admissões nos empregos formais nos últimos anos, conforme mostrado no Gráfico 1.

Outro ponto interessante é a média de rendimentos/hora, que se mostra mais elevada no trabalho secundário em relação ao principal. Nos postos formais de trabalho, o rendimento/hora médio é maior no trabalho secundário entre 100,74\% e 113,76\% em comparação com o trabalho principal. Nos informais, estes percentuais seguem a mesma lógica, variando entre $105,48 \%$ e $112,48 \%$.

É provável que os trabalhadores encontrem na informalidade do trabalho secundário uma forma de aumentarem suas receitas, embora a média de rendimentos dos informais seja menor do que a dos formais (mas como visto anteriormente, o contingente de informais é mais de $80 \%$ superior ao de formais no trabalho secundário). Uma justificativa para esta situação é que, em média, os trabalhadores informais do trabalho secundário ganham 
de $45,73 \%$ a $51,25 \%$ a mais que trabalhadores formais no trabalho principal. Ou seja, é possível que as ofertas de rendimentos mais elevadas registradas no segundo emprego estimulem os trabalhadores a optarem por esta alternativa, em vez de preencher suas horas livres com lazer.

Com relação à escolaridade, em média, observa-se que no trabalho principal os trabaIhadores formais possuem o ensino médio incompleto como nível educacional mais elevado concluído. Para os informais, esta média equivale ao ensino fundamental completo. As estatísticas corroboram com os fatos estilizados referenciados na revisão de literatura, no que diz respeito ao fato de que a informalidade é caracterizada por trabalhadores com níveis de escolaridade inferiores aos de profissionais de postos formais de trabalho.

Ao se analisar o trabalho secundário, nota-se que, em média, os trabalhadores formais possuem o ensino médio completo como nível escolar mais elevado concluído em relação aos informais, os quais possuem ensino médio incompleto como escolaridade média. Entretanto, estas médias são superiores às dos trabalhadores formais no trabalho principal. Logo, o patamar mais elevado de rendimentos observado no trabalho secundário pode estar relacionado ao nível de instrução mais alto destes trabalhadores, uma vez que os informais no trabalho secundário possuem média de escolaridade maior do que os trabalhadores formais do trabalho principal.

No que diz respeito ao gênero dos indivíduos (variável "sexo"), as estatísticas mostram que, no trabalho principal, predominam homens nos empregos formais em todos os anos investigados. Por outro lado, no trabalho secundário, a predominância dos homens é menor e há quase uma repartição igual dos postos de trabalho com as mulheres, entretanto, a maioria masculina está nos trabalhos informais. Isso pode ser um reflexo das características da informalidade no sentido de que é composta por empregos intensivos em mão de obra, que privilegiam tanto o trabalho masculino quanto o feminino. Os altos níveis de informalidade na agricultura, nos serviços e nos serviços domésticos no trabalho secundário podem sustentar esta hipótese.

Com relação à raça, observa-se que no trabalho principal os não brancos estão em maior percentual nos postos formais de trabalho, representando o maior contingente de trabalhadores. No trabalho secundário é verificado um panorama diferente: a maioria é composta por brancos nos empregos formais, mas, nos informais, os não brancos constituem a maior parte de mão de obra em todos nos anos analisados.

No trabalho principal, a idade média dos trabalhadores é semelhante entre formais e informais. Para o trabalho secundário, a média também seguiu esta mesma lógica, mas em um patamar mais elevado. Ou seja, é possível que os trabalhos secundários sejam desempenhados por trabalhadores mais velhos, que necessitam desta alternativa de renda para cobrir os gastos mensais de suas residências. Essa hipótese ganha força quando se observa que os chefes de domicílio estão em maior percentual médio nos trabalhos secundários informais, enquanto no trabalho principal esta posição no domicílio representa menos da metade dos trabalhadores. 
Embora tais estatísticas forneçam informações relevantes relacionadas ao perfil dos trabalhadores de empregos secundários, é preciso investigar com maior rigor estatístico estas hipóteses para obtenção de evidências mais consistentes. A próxima seção apresenta os resultados das estimações dos modelos econométricos propostos neste trabalho.

TABELA 4

Estatísticas descritivas Brasil - 2012-2015

\begin{tabular}{|c|c|c|c|c|c|c|c|c|}
\hline \multirow{3}{*}{ Variáveis } & \multirow{3}{*}{ Definição } & \multicolumn{7}{|c|}{ Trabalho principal } \\
\hline & & \multicolumn{2}{|c|}{2012} & \multicolumn{2}{|c|}{2013} & \multicolumn{2}{|c|}{2014} & 2015 \\
\hline & & Formal & Informal & Formal & Informal & Formal & Informal & Formal Informal \\
\hline $\begin{array}{l}\text { Rendimento/ } \\
\text { hora }\end{array}$ & $\begin{array}{l}\text { Rendimento } \\
\text { principal ou } \\
\text { secundário } \\
\text { mensal } \\
\text { dividido } \\
\text { pelas horas } \\
\text { mensais } \\
\text { trabalhadas }\end{array}$ & $(225,62)$ & $(354,36)$ & 158,76 & 113,01 & 166,18 & 121,39 & $167,60 \quad 121,71$ \\
\hline Escolaridade & $\begin{array}{l}\text { Nível de } \\
\text { instrução } \\
\text { mais elevado } \\
\text { alcançado }\end{array}$ & $\begin{array}{r}4,15 \\
(1,72)\end{array}$ & $\begin{array}{r}3,38 \\
(1,76)\end{array}$ & $\begin{array}{r}4,20 \\
(1,72)\end{array}$ & $\begin{array}{l}3,42 \\
(1,77)\end{array}$ & $\begin{array}{r}4,25 \\
(1,72)\end{array}$ & $\begin{array}{r}3,49 \\
(1,78)\end{array}$ & $\begin{array}{r}4,29 \\
(1,72)\end{array}$ \\
\hline Sexo & $\begin{array}{l}1 \text { = Homem; } \\
0=\text { Mulher }\end{array}$ & $\begin{array}{r}0,61 \\
(0,49)\end{array}$ & $\begin{array}{r}0,50 \\
(0,50)\end{array}$ & $\begin{array}{r}0,60 \\
(0,49)\end{array}$ & $\begin{array}{r}0,50 \\
(0,50)\end{array}$ & $\begin{array}{r}0,60 \\
(0,49)\end{array}$ & $\begin{array}{r}0,50 \\
(0,50)\end{array}$ & $\begin{array}{r}0,59 \\
(0,49)\end{array}$ \\
\hline Idade & $\begin{array}{l}\text { Idade do } \\
\text { indivíduo em } \\
\text { anos }\end{array}$ & $\begin{array}{r}35,03 \\
(11,26)\end{array}$ & $\begin{array}{r}34,42 \\
(13,12)\end{array}$ & $\begin{array}{r}35,24 \\
(11,31)\end{array}$ & $\begin{array}{r}34,81 \\
(13,14)\end{array}$ & $\begin{array}{r}35,58 \\
(11,37)\end{array}$ & $\begin{array}{r}35,11 \\
(13,19)\end{array}$ & $\begin{array}{r}35,97 \\
(11,43)\end{array}$ \\
\hline Raça & $\begin{array}{l}1=\text { Brancos; } \\
0=\text { Não } \\
\text { brancos }\end{array}$ & $\begin{array}{r}0,49 \\
(0,50)\end{array}$ & $\begin{array}{r}0,36 \\
(0,48)\end{array}$ & $\begin{array}{r}0,48 \\
(0,50)\end{array}$ & $\begin{array}{r}0,35 \\
(0,48)\end{array}$ & $\begin{array}{r}0,47 \\
(0,50)\end{array}$ & $\begin{array}{r}0,34 \\
(0,47)\end{array}$ & $\begin{array}{r}0,48 \\
(0,50)\end{array}$ \\
\hline $\begin{array}{l}\text { Chefe de } \\
\text { domicílio }\end{array}$ & $\begin{array}{l}1= \\
\text { Referência } \\
\text { no domicílio; } \\
0=\text { Outras } \\
\text { posições no } \\
\text { domicílio }\end{array}$ & $\begin{array}{r}0,46 \\
(0,50)\end{array}$ & $\begin{array}{r}0,40 \\
(0,49)\end{array}$ & $\begin{array}{r}0,47 \\
(0,50)\end{array}$ & $\begin{array}{r}0,42 \\
(0,49)\end{array}$ & $\begin{array}{r}0,47 \\
(0,50)\end{array}$ & $\begin{array}{r}0,42 \\
(0,49)\end{array}$ & $\begin{array}{rr}0,47 & 0,42 \\
(0,50) & (0,49)\end{array}$ \\
\hline N & & 283.181 & 130.138 & 285.788 & 126.738 & 294.292 & 126.623 & $203.451 \quad 84.728$ \\
\hline & & & & & Trabalho s & ecundário & & \\
\hline Variáveis & Definição & & 012 & & 013 & 20 & 14 & 2015 \\
\hline & & Formal & Informal & Formal & Informal & Formal & Informal & Formal Informal \\
\hline $\begin{array}{l}\text { Rendimento/ } \\
\text { hora }\end{array}$ & $\begin{array}{l}\text { Rendimento } \\
\text { principal ou } \\
\text { secundário } \\
\text { mensal } \\
\text { dividido } \\
\text { pelas horas } \\
\text { mensais } \\
\text { trabalhadas }\end{array}$ & $(448,08)$ & $(216,51)$ & $(407,74)$ & $(369,39)$ & $(424,46)$ & $(394,61)$ & $(351,75)(360,64)$ \\
\hline Escolaridade & $\begin{array}{l}\text { Nível de } \\
\text { instrução } \\
\text { mais elevado } \\
\text { alcançado }\end{array}$ & $\begin{array}{r}5,64 \\
(1,65)\end{array}$ & $\begin{array}{r}4,50 \\
(1,96)\end{array}$ & $\begin{array}{r}5,74 \\
(1,59)\end{array}$ & $\begin{array}{r}4,58 \\
(1,98)\end{array}$ & $\begin{array}{r}5,76 \\
(1,51)\end{array}$ & $\begin{array}{r}4,67 \\
(1,97)\end{array}$ & $\begin{array}{r}5,73 \\
(1,58)\end{array}$ \\
\hline
\end{tabular}




\begin{tabular}{|c|c|c|c|c|c|c|c|c|c|}
\hline \multirow[t]{2}{*}{ Sexo } & \multirow{2}{*}{$\begin{array}{l}1 \text { = Homem; } \\
0=\text { Mulher }\end{array}$} & 0,51 & 0,56 & 0,47 & 0,56 & 0,50 & 0,55 & 0,46 & 0,54 \\
\hline & & $(0,50)$ & $(0,50)$ & $(0,50)$ & $(0,50)$ & $(0,50)$ & $(0,50)$ & $(0,50)$ & $(0,50)$ \\
\hline \multirow[t]{2}{*}{ Idade } & \multirow{2}{*}{$\begin{array}{l}\text { Idade do } \\
\text { indivíduo em } \\
\text { anos }\end{array}$} & 37,06 & 37,06 & 37,30 & 37,34 & 37,32 & 37,90 & 37,51 & 38,22 \\
\hline & & $(9,92)$ & $(10,72)$ & $(9,56)$ & $(10,76)$ & $(9,45)$ & $(10,83)$ & $(9,85)$ & $(10,69)$ \\
\hline \multirow[t]{2}{*}{ Raça } & \multirow{2}{*}{$\begin{array}{l}1=\text { Brancos; } \\
0=\text { Não } \\
\text { brancos }\end{array}$} & 0,59 & 0,49 & 0,60 & 0,48 & 0,57 & 0,46 & 0,58 & 0,46 \\
\hline & & $(0,49)$ & $(0,50)$ & $(0,49)$ & $(0,50)$ & $(0,49)$ & $(0,50)$ & $(0,49)$ & $(0,50)$ \\
\hline \multirow{2}{*}{$\begin{array}{l}\text { Chefe de } \\
\text { domicílio }\end{array}$} & $\begin{array}{l}1= \\
\text { Referência }\end{array}$ & 0,52 & 0,58 & 0,53 & 0,60 & 0,56 & 0,60 & 0,51 & 0,60 \\
\hline & $\begin{array}{l}\text { no domicílio; } \\
0 \text { = Outras } \\
\text { posições no } \\
\text { domicílio }\end{array}$ & $(0,50)$ & $(0,49)$ & $(0,50)$ & $(0,49)$ & $(0,50)$ & $(0,49)$ & $(0,50)$ & $(0,49)$ \\
\hline $\mathrm{N}$ & & 1.646 & 8.047 & 1.491 & 7.790 & 1.537 & 7.258 & 1.060 & 5.194 \\
\hline
\end{tabular}

Fonte: IBGE. Pesquisa Nacional por Amostra de Domicílios - PNAD contínua de 2012, 2013, 2014e 2015. Elaboração dos autores. Nota: Desvio-padrão entre parênteses.

\section{Resultados}

Os resultados das estimações dos modelos econométricos, baseados nas equações (5), (6) e (7), são apresentados na Tabela 5. Ressalta-se que foram testadas as estimações a partir dos modelos logit, logit com efeitos fixos e logit com efeitos aleatórios, sendo este último o que apresentou os resultados mais robustos, além de solucionar os problemas de características não observáveis dos indivíduos, que podem impactar na decisão de inserir-se no trabalho secundário ou não. ${ }^{5}$ Ademais, é importante frisar que foram considerados os pesos amostrais propostos pelas PNADs contínuas.

As variáveis dependentes são binárias e apresentam três especificações para cada período analisado: possui trabalho secundário; possui trabalho secundário formal; e possui trabalho secundário informal. 0 objetivo desta estratégia é analisar se existe diferença com relação ao fato de a inserção do posto de trabalho secundário ser formal ou informal.

Os resultados mostram que o rendimento do trabalho principal influencia positivamente na decisão dos indivíduos em participar de um trabalho secundário, ou seja, quanto maior o rendimento do trabalho principal, maior é a probabilidade de inserção no trabalho secundário tanto formal quanto informal.

Dessa forma, é provável que o trabalho secundário funcione como uma alternativa de complemento de renda mensal, mesmo que os trabalhadores que optem por este mecanismo já possuam rendimentos elevados. Possivelmente, estes trabalhadores também dispõem de mais horas livres para ofertar trabalho, as quais podem ser preenchidas com o emprego secundário. Isso ocorre porque, devido aos altos rendimentos oferecidos nestes tipos de empregos, aliados à facilidade de ingresso, principalmente se informais (ULYSSEA, 2005), os maiores níveis de qualificação dos trabalhadores que compõem este

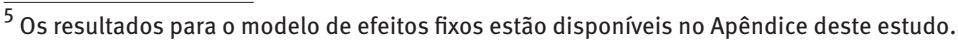


grupo perante a média da população seja um elemento crucial para se entender a composição deste tipo de mercado.

A escolaridade também afeta positivamente na escolha de ingressar no trabalho secundário, seja ele formal ou informal. Tal resultado corrobora com o que já se previa, uma vez que a média de escolaridade nos empregos secundários é maior do que no principal. Além disso, vai ao encontro da estimativa obtida para renda, pois é um fato estilizado da literatura a relação positiva entre escolaridade e rendimentos do trabalho.

Nesse sentido, a idade também mostrou um comportamento padrão, apresentando o formato de "U" invertido conforme preconiza a teoria do capital humano. Isto é, o sinal negativo da idade ao quadrado evidencia os rendimentos decrescentes do trabalho ao longo tempo. Essa situação também se confirma em relação à oferta de mão de obra, pois, à medida que a idade aumenta, mais os indivíduos tendem a optar por lazer em vez de trabalho.

Com relação ao gênero, observa-se que, para todas as especificações, o trabalho secundário não é caracterizado por ser desempenhado basicamente por mão de obra masculina. Como visto anteriormente, as atividades que apresentaram maior percentual de informalidade no trabalho secundário estão relacionadas aos serviços em geral, ou seja, empregos que não apresentam qualquer tipo de distinção de gênero para seu desempenho, e possivelmente este aspecto seja uma das justificativas por estes postos de trabalho não possuírem trabalhadores do sexo masculino de forma majoritária.

Exceto para o trabalho secundário formal em 2013, as probabilidades de inserção no trabalho secundário, no que diz respeito à raça, são maiores para trabalhadores não brancos, ou seja, não há sinais de segregação desse tipo para o mercado de trabalho secundário no Brasil. Assim como para o gênero, as estimativas para a raça dos trabalhadores indicam que este tipo de trabalho não apresenta características de segmentação, o que é um resultado relevante no sentido das medidas de inclusão adotadas no país nos últimos anos.

A posição de chefe no domicílio aumenta a probabilidade de os trabalhadores ingressarem em um trabalho secundário tanto formal quanto informal, em todo o período analisado (Tabela 5). Esse resultado era esperado, uma vez que tal posição na família requer preocupações adicionais para os trabalhadores referentes à composição da renda domiciliar para arcar com as despesas do dia a dia das residências.

As estimativas para a variável "carteira" mostram que possuir carteira assinada no trabalho principal diminui a probabilidade de o trabalhador ingressar em um trabalho secundário, em todas as especificações e períodos analisados. Isso indica, conforme a Tabela 1 já sinalizava, que as flexibilidades da informalidade no trabalho principal facilitam, também, a inserção dos trabalhadores em um trabalho secundário, sejam elas em um horário de expediente flexível, carga horária menor, etc. Além disso, é possível inferir que desempenhar atividades em postos informais no trabalho principal torna mais acessível o ingresso no trabalho secundário tanto formal quanto informal, ou seja, há nítidos incentivos para os profissionais com o perfil de renda alta e nível de escolaridade elevado buscarem 


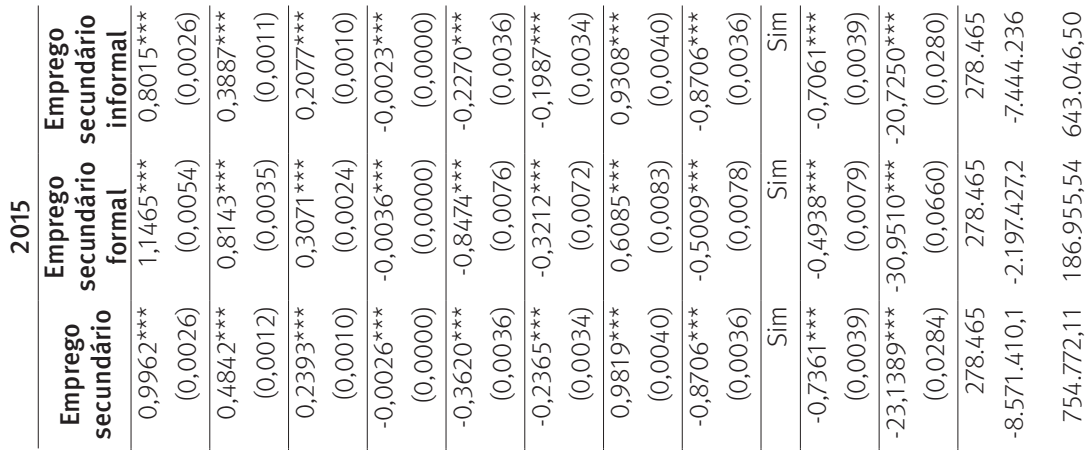

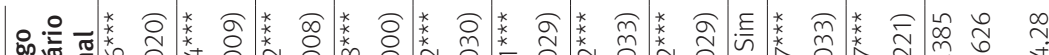

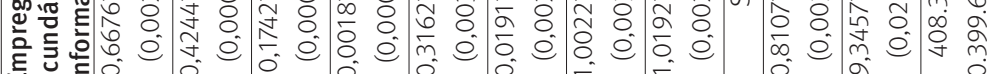

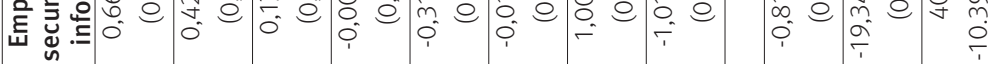

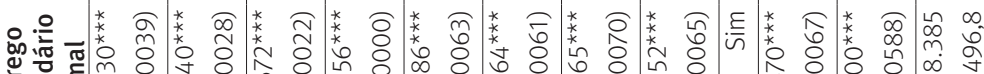

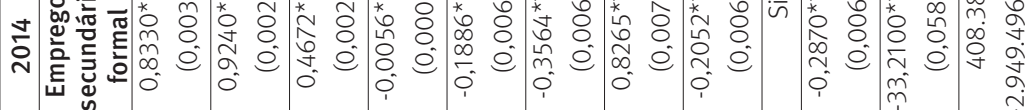

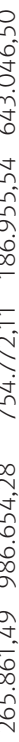

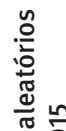

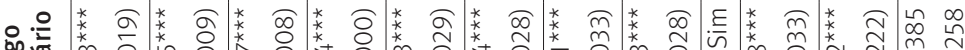

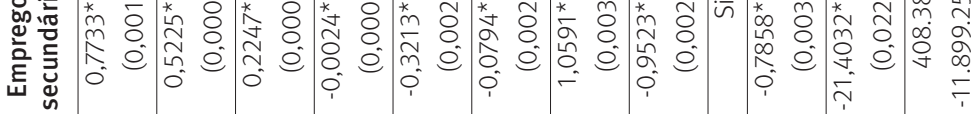

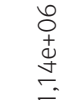

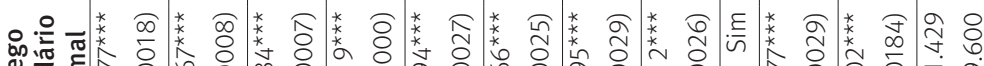

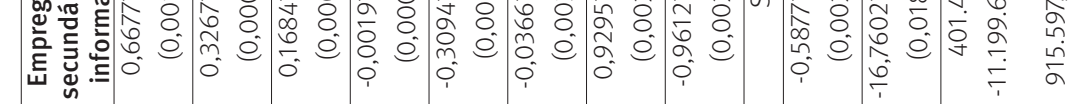

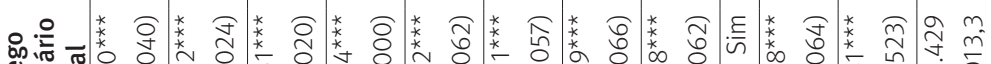

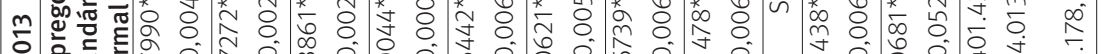

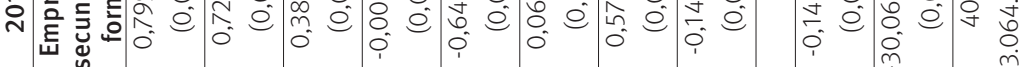
오을

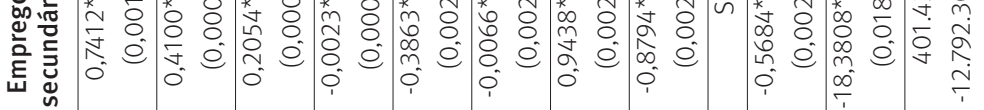

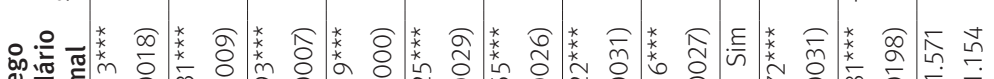

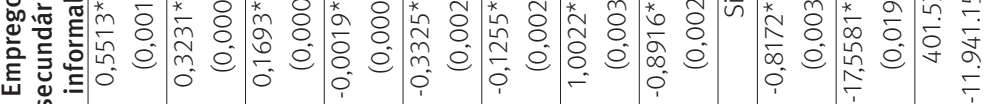

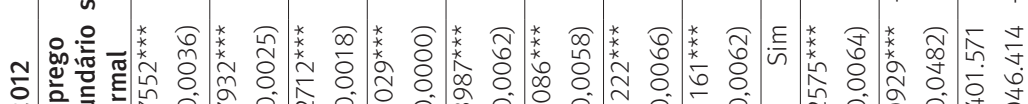

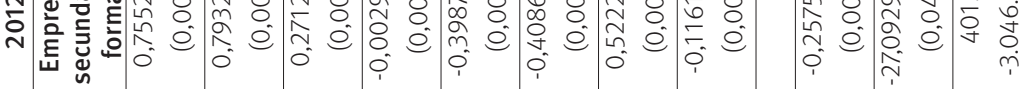

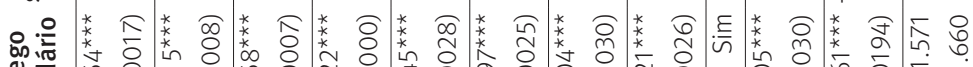

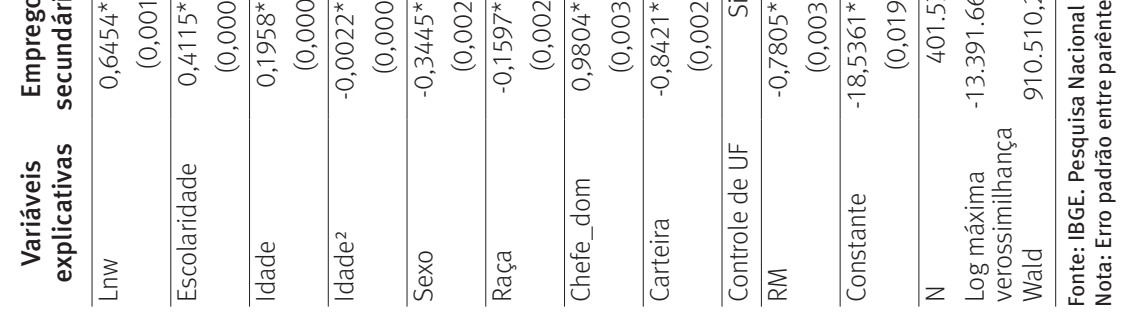


na informalidade alternativas de aumentarem ainda mais seus rendimentos mensais. Ademais, trabalhadores de regiões não metropolitanas corroboram com tal perfil, mostrando que estas características do trabalho secundário representam um cenário abrangente do mercado de trabalho brasileiro, não se restringindo apenas às regiões metropolitanas.

Por fim, é importante destacar que não há reflexos macroeconômicos diretos no cenário do mercado de trabalho secundário brasileiro, uma vez que as características se mantêm inalteradas em todo o período analisado. Dessa forma, constata-se que este tipo de trabalho é caracterizado por altos rendimentos principais, que se configuram em rendimentos secundários elevados, nível de escolaridade alto e não existência de indícios de discriminação por gênero e por raça, não somente metropolitanos e basicamente informais, ou seja, é provável que estes empregos sejam ocupados, majoritariamente, por trabalhadores classificados como profissionais liberais. ${ }^{6}$

\section{Considerações finais}

O presente estudo avaliou os determinantes do trabalho secundário e sua relação com a informalidade no mercado de trabalho brasileiro. Para tanto, estimou-se, a partir de dados da PNAD contínua, um modelo logit de efeitos aleatórios, o qual se mostrou robusto à especificação proposta. Nesse sentido, este estudo colabora com a literatura sobre informalidade ao enfocar a questão do trabalho secundário que até então, ao que se sabe, não havia sido explorada especificamente. Dessa forma, os resultados aqui apresentados permitiram o desenho do perfil deste tipo emprego, agregando evidências adicionais a tal literatura.

Os resultados apontam que existe uma predominância da informalidade no trabalho secundário, principalmente, sob a influência dos empregos informais no trabalho principal, o que é um grande problema a ser discutido especialmente no âmbito das leis que regem o mercado de trabalho. Além disso, foi possível observar que os empregos informais secundários surgem como alternativa para aqueles que já possuem elevados rendimentos no trabalho principal, como forma de aumentar suas receitas mensais sem contribuir com os impostos e taxas referentes aos empregos formais. Essa situação pode desencadear problemas no aspecto tanto da precarização das relações de trabalho como da arrecadação de tributos por parte do Estado.

Nesse sentido, o presente estudo colabora adicionalmente com elementos para a discussão relacionada ao regimento do trabalho no Brasil. Apesar de a Consolidação das Leis do Trabalho (CLT), vigente até novembro de 2017, ser ampla e possuir uma série de emendas constitucionais, sua estrutura básica apresentava sinais de não mais comportar

\footnotetext{
${ }^{6}$ Segundo a Confederação Nacional das Profissões Liberais (CNPL, 2018), a classificação "profissional liberal” refere-se "àqueles profissionais, trabalhadores, que podem exercer com liberdade e autonomia a sua profissão, decorrente de formação técnica ou superior específica, legalmente reconhecida, formação essa advinda de estudos e de conhecimentos técnicos e científicos. 0 exercício de sua profissão pode ser dado com ou sem vínculo empregatício específico, mas sempre regulamentado por organismos fiscalizadores do exercício profissional”.
} 
as atuais relações de trabalho. Embora a literatura evidencie que a fiscalização por parte do governo seja a ferramenta mais eficaz para o combate à informalidade, é provável que uma nova redação das leis trabalhistas, discutida amplamente com a sociedade e adequada aos novos modelos de trabalho existentes, consiga efetivamente diminuir o contingente populacional inserido no mercado de trabalho informal.

Em julho de 2017, o governo brasileiro alterou a redação da CLT (BRASIL, 2017) com objetivo de torná-la mais adequada às atuais formas de celebração dos contratos vigentes no mercado de trabalho. As principais mudanças foram no sentido da flexibilização da jornada de trabalho, como por exemplo os contratos de trabalho intermitentes, em que o trabalhador recebe apenas quando trabalha. Destaca-se, também, a inclusão do home office e do banco de horas como modificações relevantes no texto da lei, no sentido de

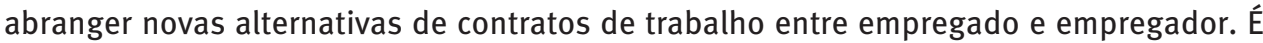
possível que estas mudanças colaborem para a diminuição da informalidade, pois permitem que os trabalhadores consigam alocar sua jornada de trabalho de acordo com suas outras atividades diárias, sejam elas laborais ou não. Por conseguinte, essa flexibilização da jornada de trabalho pode abrir espaço para os trabalhadores buscarem uma segunda fonte de renda (trabalho secundário, por exemplo), uma vez que, otimizando a alocação do seu período de trabalho no dia, é provável que surjam novas possibilidades de preenchimento do seu tempo disponível.

Embora a alteração recente da CLT pareça ter efeitos positivos em relação à diminuição da informalidade, um dos seus grandes problemas, o custo gerado ao empregador em celebrar esse tipo de contrato, pode não apresentar sinais efetivos de redução. Diante desta situação, é possível que os benefícios obtidos com a flexibilização da jornada de trabalho se tornem inócuos na busca pela redução da informalidade. Dessa forma, é preciso que se analisem estas hipóteses em estudos posteriores, para que se evidencie se esta nova adequação da CLT é realmente eficiente em seus objetivos, conforme sugeriu o governo brasileiro ao implementar tais medidas.

\section{Referências}

BARBOSA, A. L. N. H.; CORSEUIL, C. H. L. Conditional cash transfer and informality in Brazil. IZA Journal of Labor \& Development, v. 37, n. 3, p. 1-18, 2014.

BARBOSA-FILHO, F. H.; MOURA, R. L. Evolução recente da informalidade no Brasil: uma análise segundo características da oferta e demanda de trabalho. Fundação Getúlio Vargas (FGV), 2012 (Texto para Discussão, n. 17).

BARROS, R. P.; MELLO, R.; PERO, V. Informal labor contracts: a solutionor a problem? Brasília: Ipea, 1993 (Texto para Discussão, n. 291).

BRASIL. Presidência da República. Decreto-Lei no 5.452, de 1ํ de maio de 1943. Aprova a Consolidação das Leis do Trabalho. Brasília, 1943. Disponível em: 〈http://www.planalto.gov. br/ccivil_03/decreto-lei/Del5452.htm>. Acesso em: 15 fev. 2018.

. Lei no 13.467, de 13 de julho de 2017. Altera a Consolidação das Leis do Trabalho (CLT), 
aprovada pelo Decreto-Lei n. 5.452, de 10 de maio de 1943, e as Leis n. 6.019 , de 3 de janeiro de 1974, 8.036, de 11 de maio de 1990, e 8.212, de 24 de julho de 1991, a fim de adequar a legislação às novas relações de trabalho. Brasília, 2017. Disponível em: 〈http://www.planalto. gov.br/ccivil_03/_ato2015-2018/2017/lei/l13467.htm>. Acesso em: 16 jun. 2018.

CACCIAMALI, M. C. Globalização e processo de informalidade. Economia e Sociedade, v. 9, n. 1, p. 153-174, 2000.

CACCIAMALI, M. C.; FERNANDES, R. Distribuição dos trabalhadores e diferenciais de salários entre mercados de trabalho regulamentado e não regulamentado. Pesquisa e Planejamento Econômico, v. 23, n. 1, p. 135-156, 1993.

CAMARGO, J. M. Flexibilidade e produtividade do mercado de trabalho brasileiro. In: CAMACHO, J. M.; GIAMBIAGI, F. (Org.). Flexibilidade do mercado de trabalho no Brasil. Rio de Janeiro: Editora Fundação Getúlio Vargas, 1996.

CAMERON, A.; TRIVEDI, P. Microeconometrics: methods and applications. Cambridge: Cambridge University Press, 2005.

CARNEIRO, F. G.; HENLEY, A. Modelling formal vs. informal employment and earnings: microeconomic evidence for Brazil. In: XXIX ENCONTRO NACIONAL DE ECONOMIA. Anais... Salvador: Anpec, 2001.

CNPL - Confederação Nacional das Profissões Liberais. O profissional liberal. Disponível em: 〈http://www.cnpl.org.br/new/index.php/90-conteudo-estatico/767-o-profissional-liberal〉. Acesso em: 16 jun. 2018.

CURI, A. Z.; MENEZES-FILHO, N. A. Os determinantes das transições ocupacionais no mercado de trabalho brasileiro. In: XXXII ENCONTRO NACIONAL DE ECONOMIA. Anais... João Pessoa: Anpec, 2004.

FERNANDES, R. Mercado de trabalho não-regulamentado: participação relativa e diferenciais de salários. Pesquisa e Planejamento Econômico, v. 26, n. 3, p. 417-441, 1996.

GREENE, W. H.Econometric analysis. 7. ed. Boston: Prentice Hall, 2012.

HENLEY, A.; ARABSHEIBANI, G. R.; CARNEIRO, F. G. On defining and measuring the informal sector: evidence from Brazil. World Development, v. 37, n. 5, p. 992-1003, 2009.

IBGE - Instituto Brasileiro de Geografia e Estatísticas. Pesquisa Nacional por Amostragem de Domicílio (PNAD) contínua. 2017. Disponível em: 〈http://www.ibge.gov.br/home/estatistica/ indicadores/trabalhoerendimento/pnad_continua/>. Acesso em: 12 mar. 2017.

MENEGUIN, F. B.; BUGARIN, M. S. A informalidade no mercado de trabalho e o impacto das instituições: uma análise sob a ótica da teoria dos jogos. Economia Aplicada, v. 12, n. 3, p. 341-363, 2008.

MENEZES, W. F.; DEDECCA, C. S. A informalidade no mercado de trabalho brasileiro: rendimento e principais características. Revista Nexos Econômicos, v. 6, n. 2, p. 11-41, 2012.

MENEZES-FILHO, N. A.; MENDES, M.; ALMEIDA, E. S. O diferencial de salários formal-informal no Brasil: segmentação ou viés de seleção? Revista Brasileira de Economia, v. 58, n. 2, p. 235-248, 2004.

PAULA, A.; SCHEINKMAN, J. A. The informal sector: na equilibrium model and some empirical evidence from Brazil. Review of Income and Wealth, v. 57, n. s1, p. S8-S26, 2011.

PERO, V. L. A carteira de trabalho no mercado de trabalho metropolitano brasileiro. Pesquisa e Planejamento Econômico, v. 22, n. 2, p. 305-342, 1992. 
RAMOS, L. A evolução da informalidade no Brasil metropolitano: 1991-2001. Brasília: Ipea, 2002 (Texto para Discussão n. 914).

. 0 desempenho recente do mercado de trabalho brasileiro: tendências, fatos estilizados e padrões espaciais. Brasília: Ipea, 2007 (Texto para discussão n. 1255).

RAUCH, J. E. Modelling the informal sector formally. Journal of Development Economics, v. 35, p. 33-47, 1991.

SCANDIUZZI, J. C. Desemprego, informalidade e política salarial no mercado de trabalho brasileiro. Tese (Doutorado) - Pontifícia Universidade Católica do Rio de Janeiro (PUC-RJ), Rio de Janeiro, 1999.

SOARES, F. V. Some stylized facts of the informal sector in Brazil in the 1980's and 1990's. Brasília: Ipea, maio 2004 (Texto para Discussão, n. 1020).

TANNURI-PIANTO, M. E.; PIANTO, D. Informal employment in Brazil: a choice at the top and segmentation at the bottom: a quantile regression approach. 2002. Mimeografado.

ULYSSEA, G. Informalidade no mercado de trabalho brasileiro: uma resenha da literatura. Brasília: Ipea, 2005 (Texto para Discussão, n. 1070).

. Instituições e a informalidade no mercado de trabalho. Estudos Econômicos, v. 38, n. 3, p. 525-556, 2008.

WOOLDRIDGE, J. M. Econometric analysis of cross section and panel data. 2. ed. Massachusetts: The MIT Press, 2007.

\title{
Sobre os autores
}

Rafael Mesquita Pereira é doutorando em Economia Aplicada na Escola Superior de Agricultura "Luiz de Queiroz" (Esalq) da Universidade de São Paulo (USP). Professor assistente da Universidade Federal do Rio Grande (Furg).

Maria Cristina Galvão é doutoranda em Economia Aplicada na Escola Superior de Agricultura "Luiz de Queiroz" (Esalq) da Universidade de São Paulo (USP).

Henrique dos Santos Maxir é doutorando em Economia Aplicada na Escola Superior de Agricultura "Luiz de Queiroz" (Esalq) da Universidade de São Paulo (USP).

\section{Endereço para correspondência}

\author{
Rafael Mesquita Pereira \\ Rua Atahualpa Gonçalves Dias, 250, Fragata \\ 96050-050 - Pelotas-RS, Brasil. \\ Maria Cristina Galvão \\ Praça Doutor José Ataliba Leonel, 37, Codespaulo \\ 18800-000 - Piraju-SP, Brasil \\ Henrique dos Santos Maxir \\ Rua Dona Eugênia, 1430, ap. 08, Jardim Europa \\ 13416-401 - Piracicaba-SP, Brasil
}




\begin{abstract}
Determinants of secondary employment and informality: additional evidence for the Brazilian labor market

This study aims to analyze the factors that determine an individual's choice of having secondary employment and how this decision is related to informality. To that end, based on data from "Pesquisa Nacional por Amostra de Domicílios (PNAD) contínua", we estimate a random effects Logit model to verify factors influencing this decision of insertion. Results indicate that the main work income, schooling and informality in the main employment have a positive influence on the worker's decision to seek secondary employment.
\end{abstract}

Keywords: Random effects logit model. Secondary employment. Informal employment.

\title{
Resumen
}

Determinantes del empleo secundario e informalidad: evidencias adicionales para el mercado de trabajo brasileño

El objetivo de este estudio es analizar los factores que determinan la elección de un individuo de tener un empleo secundario y cómo esta decisión está relacionada con la informalidad. Para ello, a partir de los datos de la Pesquisa Nacional por Amostra de Domicílios (PNAD) contínua, se estima un modelo logit de efectos aleatorios para verificar los factores que influyen en esta decisión de inserción laboral. Los resultados apuntan a que el rendimiento del trabajo principal, la escolaridad y la informalidad en el empleo principal influyen positivamente en la decisión de los trabajadores de obtener en un empleo secundario.

Palabras clave: Modelo logit de efectos aleatorios. Segundo empleo. Empleo informal.

Recebido para publicação em 18/10/2017

Aceito para publicação em 21/06/2018 


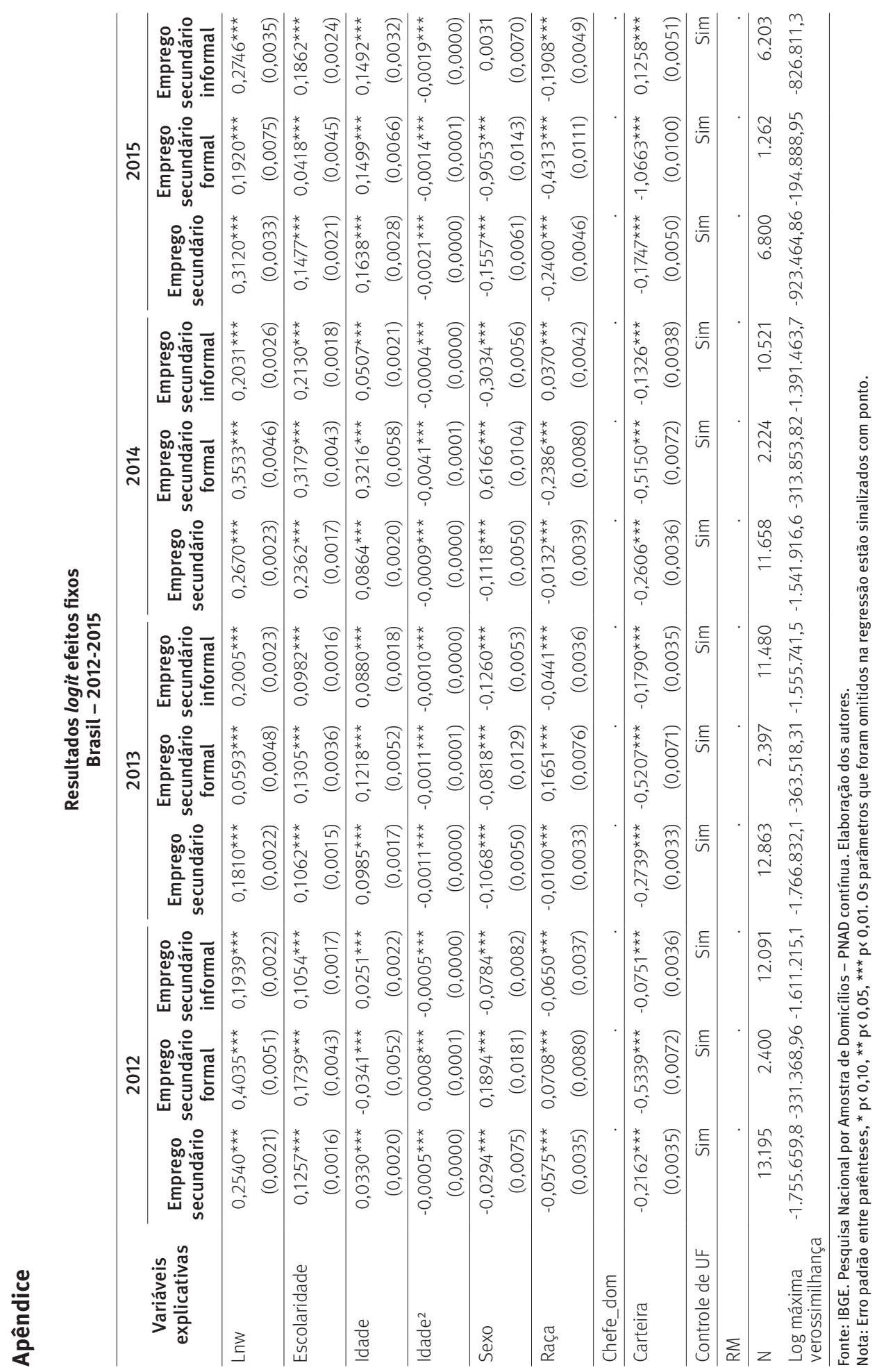

